\title{
Clinical Pharmacology and Therapeutic Drug Monitoring of Immunosuppressive Agents
}

\author{
Ana Luisa Robles Piedras, \\ Minarda De la O Arciniega and \\ Josefina Reynoso Vázquez \\ Additional information is available at the end of the chapter \\ http://dx.doi.org/10.5772/54910
}

\section{Introduction}

Immunosuppressive drugs are used to reduce the immune response in organ transplantation and autoimmune disease. In transplantation, the major classes of immunosuppressive drugs used today are: (1) glucocorticoids, (2) calcineurin inhibitors, (3) antiproliferative/antimetabolic agents, and (4) biologics (antibodies). These drugs have met with a high degree of clinical success in treating conditions such as acute immune rejection of organ transplants and severe autoimmune diseases. However, such therapies require lifelong use and nonspecifically suppress the entire immune system, exposing patients to considerably higher risks of adverse effects [1].

The pharmacokinetics of the immunosuppressive drugs is complex and unpredictable. A narrow therapeutic index unique to each patient, as well as variable absorption, distribution, and elimination, are characteristics of these drugs. Therapeutic drug monitoring plays a key role in helping clinicians maintain blood and plasma levels of immunosuppressive drugs within their respective therapeutic ranges. Variation in concentrations outside the narrow therapeutic ranges can result in adverse clinical outcomes. Therapeutic drug monitoring ensures that concentrations are not too high or too low, thereby reducing the risks of toxicity or rejection, respectively. This chapter briefly reviews some immunosuppressive drugs: cyclosporine, tacrolimus, mycophenolic acid, sirolimus, everolimus, azathioprine, daclizumab and basiliximab, alemtuzumab and glucocorticoids. A general discussion of mechanism of action and side effects of these immunosuppressive agents used more commonly today are described below, followed by an overview of general principles of therapeutic drug monitoring 
and concluding with brief information about monitoring of individual immunosuppressive agents as well as a brief description of future trends in immunosuppression therapy.

\section{Mechanism of action and side effects}

\subsection{Cyclosporine A (CsA)}

CsA is a cyclic polypeptide immunosuppressant consisting of 11 amino acids. It is produced as a metabolite of the fungus species Tolypocladium inflatum Gams. CsA generally is recognized as the agent that ushered in the modern era of organ transplantation, increasing the rates of early engraftment, extending kidney graft survival, and making cardiac and liver transplantation possible. Clinical indications for CsA are kidney, liver, heart, and other organ transplantation; rheumatoid arthritis; and psoriasis. The dose of CsA varies, depending on the organ transplanted and the other drugs used in the specific treatment protocols. Dosage is guided by signs of rejection (too low a dose), renal or other toxicity (too high a dose), and close monitoring of blood levels [1].

\subsubsection{Mechanism of action}

CsA suppresses some humoral immunity, but is more effective against T-cell-dependent immune mechanisms such as those underlying transplant rejection and some forms of autoimmunity. Its actions appear to be dependent upon binding to intracellular sites of action. Because of its high lipophilicity, CsA enters cells easily to gain access to the site of action [1]. The intracellular protein most closely linked to the immunosuppressive activity of CsA is cyclophilin. CsA forms a complex with cyclophilin, a cytoplasmic receptor protein present in target cells. This complex binds to calcineurin to block its phosphatase activity (Table 1). Calcineurin-catalyzed dephosphorylation is required for movement of a component of the nuclear factor of activated T lymphocytes (NFAT) into the nucleus. Calcineurin phosphatase activity is inhibited after physical interaction with the cyclosporine/cyclophilin complex. This prevents $\mathrm{Ca}^{2+}$-stimulated dephosphorylation of the cytosolic component of NFAT such that NFAT does not enter the nucleus, gene transcription is not activated, and the T lymphocyte fails to respond to specific antigenic stimulation. By binding to cyclophilin, the antigenic response of helper $\mathrm{T}$ lymphocytes is inhibited; the production of interleukin-2 and interferongamma is suppressed [2-3]. In addition, production of the receptor site for interleukin-2 on T lymphocytes is inhibited by CsA and also increases expression of transforming growth factor$\beta$ (TGF- $\beta$ ), a potent inhibitor of IL-2-stimulated Tcell proliferation and generation of cytotoxic T lymphocytes (CTL) [4-8].

\subsubsection{Side effects}

The principal side effects to CsA therapy are hypertension, nephrotoxicity, tremor, hirsutism, hyperlipidemia, nausea and vomiting, gingival hyperplasia, and hepatotoxicity [1,9]. Hypertension is a common adverse effect of CsA, with the incidence decreasing over time. Generally, 
mild to moderate hypertension may occur in approximately $50 \%$ of renal transplant patients and most cardiac transplant patients. In liver transplant patients $(n=75), 27 \%$ experienced hypertension. Incidence: $13 \%$ to $53 \%$ [9]. Discontinuation of CsA therapy may be required for persistent blood pressure elevation despite adjustments in therapy. Antihypertensive agents such as calcium-channel blockers may be used, with isradipine and nifedipine most appropriate since they do not interfere with CsA metabolism. Other calcium-channel blockers (eg, diltiazem and verapamil) may increase cyclosporine levels. Patients with preexisting hypertension controlled by beta-blockers may continue to receive the same therapy. Angiotensin converting enzyme inhibitors and diuretics are not recommended [10]. Probable mechanisms for cyclosporine induced hypertension involve increased prostaglandin synthesis, decreased free water excretion, and decreased sodium and potassium excretion [11]. CsA is nephrotoxic, the mechanism by which CsA causes nephrotoxicity is attributed to changes in vasomotor tone induced by activation of the sympathetic nervous system [12]. Tremor was reported to appear within a few days of initiating CsA therapy and was considered dose dependent. Incidence: $12 \%$ to $55 \%$ [9].

\begin{tabular}{cc}
\hline Immunosuppressive agent & Site of Action \\
\hline Cyclosporine and tacrolimus & $\begin{array}{c}\text { Calcineurin (inhibits phosphatase } \\
\text { activity) }\end{array}$ \\
\hline Mycophenolic acid & $\begin{array}{c}\text { Inosine monophosphate dehydrogenase } \\
\text { (inhibits activity) }\end{array}$ \\
\hline Sirolimus and everolimus & $\begin{array}{c}\text { Protein kinase involved in cellcycle } \\
\text { progression (mTOR) (inhibits activity) }\end{array}$ \\
\hline Azathioprine & $\begin{array}{c}\text { Deoxyribonucleic acid (false } \\
\text { nucleotide incorporation) }\end{array}$ \\
\hline Daclizumab and basiliximab & IL-2 receptor (block IL-2-mediated \\
T-cell activation)
\end{tabular}

Table 1. Sites of action of immunosuppressive agents on T-cell activation [1]

Administration of CsA adversely affects plasma lipoprotein and cholesterol levels causing hyperlipidemia [9]. In a study CsA increased total cholesterol by $21 \%$, low-density lipoproteins by $31 \%$, and apolipoproteins by $12 \%$ over 27 days [13]. Gingival hyperplasia was reported in $4 \%$ to $16 \%$ of patients treated with CsA [9]. Histologically, CsA-induced gingival overgrowth is characterized by cellular hyperplasia along with myxomatous changes and accumulation of collagen [14]. Reduction of the dose of CsA may result in complete resolution of gingival hyperplasia $[15,16]$. 


\subsection{Tacrolimus (TRL)}

TRL (Prograf $®$ ) is a macrolide antibiotic produced by Streptomyces tsukubaensis. It is practically insoluble in water. TRL is indicated for the prophylaxis of solid-organ allograft rejection in a manner similar to CsA. The recommended starting dose for TRL injection is 0.03 to 0.05 $\mathrm{mg} / \mathrm{kg}$ per day as a continuous infusion. Recommended initial oral doses are 0.15 to 0.2 $\mathrm{mg} / \mathrm{kg}$ per day for adult kidney transplant patients, in two divided doses 12 hours apart. These dosages are intended to achieve typical blood trough levels in the 5 to $15 \mathrm{ng} / \mathrm{mL}$ range. Pediatric patients generally require higher doses than do adults $[1,17]$.

\subsubsection{Mechanism of action}

The compound is chemically distinct from CsA but both agents elicit similar immunosuppressant effects. TRL suppresses both humoral (antibody) and cell-mediated immune responses. Like CsA, TRL inhibits Tcell activation by inhibiting calcineurin [17]. The proposed mechanism for this effect is binding to an intracellular protein FK506-binding protein-12 (FKBP-12), immunophilin structurally related to cyclophilin. A complex of tacrolimusFKBP-12, Ca2+, calmodulin, and calcineurin then forms, which inhibits the phosphatase activity of calcineurin (Table 1). As described for CsA the inhibition of phosphatase activity prevents dephosphorylation and nuclear translocation of NFAT and inhibits T-cell activation. Thus, although the intracellular receptors differ, CsA and TRL target the same pathway for immunosuppression [1,18]. The immunosuppressive activity of TRL is, however, more marked than that of CsA. Studies on cultured CD4+ (T-helper) lymphocytes have demonstrated that TRL is at least 100 times more potent than CsA (weight basis) in selectively inhibiting secretion of various cytokines (i.e., interleukin-2, interleukin-3, interferon-gamma) $[19,20]$. The action of TRL on lymphocytes is more difficult to reverse than that of CsA; this may be attributable to the effect of TRL on impairing the expression of interleukin-2 receptors on alloantigen-stimulated T-cells [19]. TRL possesses another important effect in addition to the inhibition of IL-2 gene transcription, to be exact the ability to act as a general inhibitor of the protein secretory pathway, which strongly suggests that the diabetogenic effect of the TRL could be caused by the blockade of insulin secretion. This novel effect also provides an explanation for other side-effects observed in immunosuppressive treatment $[1,21,22]$.

\subsubsection{Side effects}

TRL is an established immunosuppressant for the prevention and treatment of allograft rejection in organ transplantation. However, TRL therapy also has several adverse effects like nephrotoxicity, hypertension, hyperkalemia, hyperglycemia, hyperlipidemia, neurotoxicity (tremor, headache, dizziness, seizure), gastrointestinal complaints, and diabetes are all associated with TRL use [18].

Nephrotoxicity has been reported with TRL therapy, particularly when used in high doses. Incidence: $36 \%$ to $59 \%$ [23]. Acute nephrotoxicity is characterized by an increased serum creatinine and/or a decrease in urine output, and is generally reversible. Chronic nephrotoxicity is associated with increased serum creatinine, decreased kidney graft life, and character- 
istic histologic changes observed on renal biopsy; these changes are usually progressive. Renal function should be monitored closely $[23,24]$. In systemic formulations hypertension occurred in $13 \%$ to $89 \%$ of patients receiving TRL in clinical trials. Antihypertensive therapy may be required. Potassium sparing diuretics, ACE inhibitors, and angiotensin receptor blockers should be used with careful consideration since due to the potential to cause hyperkalemia. Calcium channel blockers may be effective in treating TRL associated hypertension, but caution is warranted since interference with TRL metabolism may require a dosage reduction. $[23,25]$. Hyperlipidemia was reported as one of the more common adverse events in TRLtreated heart transplant recipients. Incidence: $10 \%$ to $34 \%$ [23]. In clinical trials tremor has occurred in $15 \%$ to $56 \%$ of patients receiving TRL $[23,26]$. In systemic formulations headache occurred in $24 \%$ to $64 \%$ of patients receiving TRL in clinical trials. Headache may respond to a dosage reduction [23]. In clinical trials hyperglycemia occurred in $21 \%$ to $70 \%$ of patients receiving TRL [23]. New onset diabetes mellitus has been reported in kidney, liver, and heart transplant patients receiving TRL therapy. Incidence: $11 \%$ to $22 \%$. Close monitoring of blood glucose concentrations is recommended $[23,27]$.

\subsection{Mycophenolic acid (MPA)}

MPA is a secondary metabolite produced by Penicillium brevicompactum, which has antibiotic and immunosuppressive properties used to prevent rejection of solid organ transplants [28]. It is highly soluble in aqueous media at physiological $\mathrm{pH}$. The drug is marketed as the ester prodrug mycophenolate mofetil (CellCept $\left.{ }^{\circledR}\right)(\mathrm{MMF})$ for kidney, liver, and heart transplants or enteric-coated mycophenolate sodium (Myfortic $\left.{ }^{\circledR}\right)$ for kidney transplants $[1,29]$.

\subsubsection{Mechanism of action}

MPA produces potent selective, noncompetitive, and reversible inhibition of inosine monophosphate dehydrogenase (IMPDH), an important enzyme in the de novo pathway of guanine nucleotide synthesis (Table 1). B and T lymphocytes are highly dependent on this pathway for cell proliferation, while other cell types can use salvage pathways; MPA therefore selectively inhibits lymphocyte proliferation and functions, including antibody formation, cellular adhesion, and migration [1,30]. In vitro and in vivo studies have demonstrated the ability of MPA to block proliferative responses of $\mathrm{T}$ and $\mathrm{B}$ lymphocytes, and inhibit antibody formation and the generation of cytotoxic T-cells [31]. In a preclinical study in mice, MPA increased survival of heart and pancreatic islet cell allografts. Studies in rats have also demonstrated prolonged heart allograft survival, as well as reversal of acute rejection and prevention of rejection in the sensitized animal. Antirejection effects have been attributed to decreased recruitment of activated lymphocytes to the graft site [32].

\subsubsection{Side effects}

The principal adverse effects of MPA are gastrointestinal, these include diarrhea, nausea and vomiting; hypertension; hematologic effects (anemia and leukopenia) and neurologic effects (anxiety asthenia dizziness headache insomnia tremor). There also is an increased incidence of some infections, especially sepsis associated with cytomegalovirus [1,33-35]. Diarrhea was 
reported in $36.1 \%$ of renal transplant patients, $45.3 \%$ of cardiac transplant patients, and $51.3 \%$ of hepatic transplant patients in a clinical study. Vomiting was reported in $33.9 \%$ of cardiac transplant patients, and $32.9 \%$ of hepatic transplant patients. Nausea was reported in $23.6 \%$ of renal transplant patients, $54 \%$ of cardiac transplant patients, and $54.5 \%$ of hepatic transplant. The incidence of adverse gastrointestinal complications requiring dose reduction. Usually occurs early in therapy and respond to dose reduction or switching from two to three divided daily doses [34].

Hypertension was reported in $28.2 \%$ of renal transplant patients, $77.5 \%$ of cardiac transplant patients, and $62.1 \%$ of hepatic transplant patients [34]. Leukopenia was $23.2 \%$ and $34.5 \%$ in renal transplant, $30.4 \%$ in cardiac transplant, and $45.8 \%$ in hepatic transplant in a clinical study. Complete blood counts should be performed weekly during the first month, twice monthly for the second and third months of treatment, then monthly through the first year [34].

\subsection{Sirolimus (SRL) and Everolimus (EVL)}

SRL(also known as Rapamycin and Rapamune ${ }^{\circledR}$ ) is a macrocyclic lactone produced by the actinomycete Streptomyces hygroscopicus, with immunosuppressive, antitumor, and antifungal properties. SRL appears to be synergistic with CsA in kidney transplantation, but with a different side-effect profile. It is an immunosuppressive agent of potential benefit in clinical liver transplantation. EVL is an analogue of SRL with immunosuppressive and antiproliferative activity. It is closely related chemically and clinically to SRL but has distinct pharmacokinetics. The main difference is a shorter half-life and thus a shorter time to achieve steady state concentrations of the drug $[1,36]$.

\subsubsection{Mechanism of action of SRL}

SRL has been demonstrated to block the response of T- and B-cell activation by cytokines, which prevents cell-cycle progression and proliferation. Intracellularly, sirolimus forms a complex with cytosolic FK-binding proteins, primarily FKBP-12, considered essential for functionality; however, the sirolimus-FKBP-12 complex does not affect calcineurin activity. It binds to and inhibits a protein kinase, designated mammalian target of rapamycin (mTOR) (Table 1), which is a key enzyme in cell-cycle progression. Inhibition of mTOR blocks cell-cycle progression at the G1 to S phase transition $[37,38]$. Specific biochemical steps inhibited by SRL include activation of p70S6 kinase, activation of the cdk2/cyclinE complex, and phosphorylation of retinoblastoma protein $[37,38]$. SRL appears to be less nephrotoxic than CsA and TRL; this may be related to its lack of effect on calcineurin [1,38]. In preclinical studies (in vitro and in vivo), additive or synergistic immunosuppressive effects were observed when SRL was combined with TRL, CsA, MMF, and brequinar [37].

\subsubsection{Side effects of $S R L$}

The use of SRL in renal transplant patients is associated with a dose-dependent increase in serum cholesterol and triglycerides that may require treatment. Other studies have identified hyperlipidemia and thrombocytopenia as significant SRL side effects [39]. In the other hand, 
while immunotherapy with SRL per se is not nephrotoxic, patients treated with CsA plus SRL have impaired renal function compared to patients treated with CsA and either azathioprine or placebo. Renal function therefore must be monitored closely in such patients. Other adverse effects include anemia, leukopenia, thrombocytopenia, hypokalemia or hyperkalemia, fever, and gastrointestinal effects. Delayed wound healing may occur with SRL use. As with other immunosuppressive agents, there is an increased risk of neoplasms, especially lymphomas, and infections $[1,36,37]$.

\subsubsection{Mechanism of action of EVL}

Like SRL, EVL binds to the cytosolic immunophyllin FKBP12; both agents inhibit growth factor-driven cell proliferation, including that of T-cells and vascular smooth muscle cells. After binding to and forming a complex with the cytoplasmic protein FKBP-12, this complex binds to and inhibits the mammalian Target Of Rapamycin (mTOR) and phosphorylates P70 S6 ribosomal protein kinase (a substrate of mTOR) (Table 1). The phosphorylation of P70 S6 ribosomal protein kinase by the EVL complex prevents protein synthesis and cell proliferation. The EVL:FKBP-12 complex does not affect calcineurin activity [40,41]. Binding of EVL to FKBP12 is weaker than that of SRL (about 3-fold), related to 40-O-alkylation, and this correlates with a 2- to 3-fold lower in vitro immunosuppressive activity for EVL. However, the oral in vivo activity of EVL has been at least equipotent to oral SRL in several animal allotransplantation/autoimmune disease models. This appears related to the chemical modification in EVL (2-hydroxyethyl chain), providing more favorable pharmacokinetic properties (eg, absorption, disposition) which compensate for relatively poor in vitro activity [40]. EVL and SRL antagonize TRL based calcineurin inhibition via saturation of FKBP12 [1,42].

\subsubsection{Side effects of EVL}

Side effects seem to be the same as with SRL [1]. Endocrine abnormalities, including hyperlipidemia and hypertriglyceridemia, have been reported with EVL treatment. Monitoring for hyperlipidemia is recommended in all patients; diet, exercise, and lipid lowering therapy should be initiated if hyperlipidemia occurs. In a clinical study with EVL, the most important causes of discontinuation in 69 patients were severe infections $(2.3 \%)$, pneumonitis $(6.8 \%)$, acute rejection episode (4.1\%), proteinuria (4.1\%). Although the overall incidence discontinuation due to side effects was higher in the EVL than SRL group, there was no greater frequency of severe side effects $[43,44]$.

\subsection{Azathioprine}

Azathioprine is a purine antimetabolite. It is an imidazolyl derivative of 6-mercaptopurine. Azathioprine was first introduced as an immunosuppressive agent in 1961, helping to make allogeneic kidney transplantation possible. It is indicated as an adjunct for prevention of organ transplant rejection and in severe rheumatoid arthritis. It has long been used as a steroid sparing agent in a variety of clinical scenarios [1,45]. In the United States azathioprine was usually combined with prednisone and CsA. Azathioprine was regarded as an adjunctive agent to CsA and the combination was often called "triple therapy". The term "adjunctive 
agent" is used to describe the immunosuppressive drugs that are used, or were developed for use, in combination with a calcineurin inhibitor to enhance the potency of the immunosuppressive protocol, as measured by a decreased incidence of acute rejection episodes [46].

\subsubsection{Mechanism of action}

Azathioprine inhibits purine metabolism. Following exposure to nucleophiles such as glutathione, azathioprine is cleaved to 6-mercaptopurine, which in turn is converted to additional metabolites that inhibit de novo purine synthesis. 6-thio-IMP, a fraudulent nucleotide, is converted to 6-thio-GMP and finally to 6-thio-GTP, which is incorporated into DNA. Cell proliferation is thereby inhibited, impairing a variety of lymphocyte functions. Azathioprine appears to be a more potent immunosuppressive agent than 6-mercaptopurine, which may reflect differences in drug uptake or pharmacokinetic differences in the resulting metabolites $[1,45]$.

\subsubsection{Side effects}

The major side effect of azathioprine is bone marrow suppression, including leukopenia (common), and thrombocytopenia (less common). Other important adverse effects include increased susceptibility to infections (especially varicella and herpes simplex viruses) and hepatotoxicity [1].

\subsection{Anti-IL-2 receptor (Anti-CD25) antibodies}

There are two anti-IL-2R preparations for use in clinical transplantation: daclizumab and basiliximab. These are used for prophylaxis of acute organ rejection in adult patients. Basiliximab is considered a chimeric antibody, because it consists of approximately $70 \%$ human and $30 \%$ murine proteins. This agent has low immunogenicity potential due to the incorporation of human protein sequences. Daclizumab consists of $90 \%$ human and $10 \%$ murine components. The effectiveness of daclizumab is comparable to that of basiliximab, with an adverse-effect profile comparable to that seen with placebo $[1,46]$.

\subsubsection{Mechanism of action}

Basiliximab binds with high affinity to the alpha subunit of the IL-2 receptor, also known as CD25, where it acts as a receptor antagonist. The antagonistic effect on the IL-2 receptor prevents T-cell activation and subsequent proliferation without causing lysis or cell destruction. Daclizumab, like basiliximab, is a nondepleting monoclonal antibody that acts as an antagonist at the CD25 subunit of T cells and received marketing approval in 1997 for induction therapy in renal transplant recipients. In Phase III trials, the half-life of daclizumab was 20 days, resulting in saturation of the IL-2R $\alpha$ on circulating lymphocytes for up to 120 days after transplantation. In these trials, daclizumab was used with maintenance immunosuppression regimens (CsA, azathioprine, and steroids; CsA and steroids). Subsequently, daclizumab was successfully used with a maintenance triple-therapy regimen-either with CsA or TRL, steroids, and MMF substituting for azathioprine. In the Phase III trials, the half-life of basilix- 
imab was 7 days. In one randomized trial, basiliximab was safe and effective when used in a maintenance regimen consisting of CsA, MMF, and prednisone [1,47].

\subsubsection{Side effects}

No cytokine-release syndrome has been observed with these antibodies, but anaphylactic reactions can occur. Although lymphoproliferative disorders and opportunistic infections may occur, as with the depleting antilymphocyte agents, the incidence ascribed to anti-CD25 treatment appears remarkably low. No significant drug interactions with anti-IL-2-receptor antibodies have been described $[46,47]$.

\subsection{Alemtuzumab}

The antibody alemtuzumab is a recombinant DNA-derived humanized monoclonal antibody that is directed against the cell surface glycoprotein CD52, which is expressed on the surface of normal and malignant $\mathrm{B}$ and $\mathrm{T}$ lymphocytes, NK cells, monocytes, macrophages, and tissues of the male reproductive system; thus, the drug causes extensive lympholysis by inducing apoptosis of targeted cells. It has achieved some use in renal transplantation because it produces prolonged T- and B-cell depletion and allows drug minimization [1,47].

\subsubsection{Mechanism of action}

Alemtuzumab antibody binds to CD52, it triggers an antibody-dependent lysis of these cells. The depletion of lymphocytes is so marked that it takes several months or up to one year postadministration for a patient's immune system to be fully reconstituted $([1,47]$.

\subsubsection{Side effects}

Alemtuzumab's mechanism of depletion is so profound that its adverse-effect profile occurs frequently and with a high level of severity. Adverse effects associated with alemtuzumab use include neutropenia (70\%), thrombocytopenia (52\%), anemia (47\%), nausea (54\%), vomiting $(41 \%)$, diarrhea $(22 \%)$, headache $(24 \%)$, dysesthesias $(15 \%)$, dizziness $(12 \%)$, and autoimmune hemolytic anemia $(<5 \%)[47]$.

\subsection{Glucocorticoids}

The introduction of glucocorticoids as immunosuppressive drugs in the 1960s played a key role in making organ transplantation possible. Steroids are a cornerstone of immunosuppressive therapy in kidney transplantation despite their side effects and morbidity. More than 95\% of transplant recipients are treated with steroids as a usual component of clinical immunosuppressive regimens. Prednisone, prednisolone, and other glucocorticoids are used alone and in combination with other immunosuppressive agents for treatment of transplant rejection and autoimmune disorders $[1,48]$. Transplantation specialists are now moving toward protocols that reduce the incidence of infections and minimize adverse events. Most immunosuppressive regimens are currently based on the combination of calcineurin inhibitors (CsA, TRL) with antiproliferative agents (azathioprine, MMF) and steroids (prednisone) [49]. 


\subsubsection{Mechanism of action}

Glucocorticoids lyse (in some species) and induce the redistribution of lymphocytes, causing a rapid, transient decrease in peripheral blood lymphocyte counts. To effect longer-term responses, steroids bind to receptors inside cells; either these receptors, glucocorticoid-induced proteins, or interacting proteins regulate the transcription of numerous other genes. Additionally, glucocorticoid-receptor complexes increase I $\mathrm{B} B$ expression, thereby curtailing activation of NF- $\kappa \mathrm{B}$, which increases apoptosis of activated cells. Of central importance, key proinflammatory cytokines such as IL- 1 and IL- 6 are down regulated. T cells are inhibited from making IL-2 and proliferating. The activation of cytotoxic T lymphocytes is inhibited. Neutrophils and monocytes display poor chemotaxis and decreased lysosomal enzyme release. Therefore, glucocorticoids have broad anti-inflammatory effects on multiple components of cellular immunity [1].

\subsubsection{Side effects}

Steroids are effective in reducing the incidence of acute rejection but are an important cause of morbidity and probably mortality. Moreover, they have adverse effects on cardiovascular risk factors such as hypertension, hyperglycemia, or hyperlipidemia, deleterious effects on bone metabolism, and may contribute to an increased risk of infection $[1,48]$.

\section{General principles of Therapeutic Drug Monitoring (TDM)}

A basic tenet of clinical pharmacology is that the pharmacologic activity of an exogenously administered agent is related to the free drug concentration available at its receptor or ligandbinding site. A mayor underlying hypothesis in clinical pharmacokinetics is that the concentration of the agent in blood, serum or some other measurable compartment is related to the concentration of free (or non-bound) drug at its effector site [50]. Drugs are administered to achieve a therapeutic objective. Once this objective is defined, a drug and its dosage regimen are chosen for the patient. Drug therapy is subsequently managed together with steps required to initiate therapy, this management is usually accomplished by monitoring incidence and intensity of both therapeutic and toxic effects.

\subsection{Therapeutic range}

The therapeutic range (therapeutic index) is the ratio between the toxic dose and the therapeutic dose of a drug. The closer this ratio is to 1 , the more difficult the drug is to use in clinical practice. The therapeutic index for immunosuppressant drugs is very low, whereas that for amoxicillin is extremely high. Clinical use of drugs with a narrow therapeutic index has led to the monitoring of drug concentrations in patients - therapeutic drug monitoring - in which the plasma concentration of a drug is measured and the dose adjusted to achieve a desired therapeutic drug concentration. Generally defined as the range of drug concentrations associated with maximal efficacy and minimal toxicity, there is currently no standard defining 
an acceptable level of toxicity or efficacy, nor are there consistent procedures used to establish a therapeutic range [51].

In general, a therapeutic range should never be considered in absolute terms, as it represents no more than a combination of probability charts. In other words, a therapeutic range is a range of drug concentrations within which the probability of the desired clinical response is relatively high and the probability of unacceptable toxicity is relatively low [52].

Since the development of the range is probabilistic in nature, a concentration that is within the "therapeutic range" for a given drug does not exclude the possibility that signs and symptoms of toxicity experienced by an individual patient are related to the monitored drug. A concentration outside of the range also does not indicate that a patient will experience toxicity or reduced efficacy; however, the likelihood of either is certainly lower [51]. It is important to recognize that the therapeutic range is not necessarily valid outside of the population used to establish it. This is particularly critical for immunosuppressive drugs, as most patients that are treated with these drugs receive additional immunosuppressive agents. A change in dosing of one drug may have a profound impact on the pharmacodynamic relationship of another. The nature of the transplanted organ (e.g., cadaveric versus living-related donor kidneys), age, and co-morbid illness can all have important influences on the pharmacodynamic response. The importance of these factors should not be ignored [51].

\subsection{Interpretation of plasma drug concentration}

The process of selecting the most appropriate dosage regimen to achieve concentrations in a relatively narrow range may be complicated by unpredictable intrapatient and interpatient variability in the drug's pharmacokinetics. A sophisticated application of pharmacokinetic principles, incorporating prior and subsequent measures of drug concentration and effects, can improve the quality of one's predictions. Although a single "best" approach to using drug concentrations does not exist for every drug, it is imperative to realize that without a systematic approach to therapeutic drug concentration monitoring, drug concentrations may be uninterpretable, unhelpful and potentially harmful. It thus becomes essential to recognize the key elements of clinical pharmacokinetics and pharmacodynamics, and to develop strategies to perform and use them most effectively [52].

There are a number of advantages to therapeutic drug monitoring that provide the clinician with clinically useful information. Plasma drug concentrations in conjunction with a thorough assessment of the patient's clinical status and the therapeutic goals to be achieved provide a means of successfully and rapidly individualizing a patient's therapeutic regimen to assure optimal benefits con minimal risk. Therapeutic drug measuring is only one part of therapeutic drug monitoring that provides expert clinical interpretation of drug concentration as well as evaluation based on pharmacokinetic principles. Expert interpretation of a drug concentration measurement is essential to ensure full clinical benefit. Clinicians routinely monitor drug pharmacodynamics by directly measuring the physiological indices of therapeutic responses, such as lipid concentrations, blood glucose, blood pressure, and clotting [53]. 
Anyone involved in the utilization of information derived from TDM must always bear in mind that the interpretation of plasma drug concentration must always be carried out in conjunction with an assessment of the clinical status of the patient. Therapeutic ranges should more correctly be described as optimal concentrations. According to the definition mentioned above, the therapeutic range (optimal concentration) of a drug is that concentration of drug present in plasma or some other biologic fluid or tissue that provides the desired therapeutic response in most patients. The severity of the disease process determines the amount of drug necessary to achieve a given therapeutic effect. Thus, it is quite possible that a patient may achieve the desired therapeutic effect at a plasma concentration well below the optimal range. Conversely, some patients will not achieve the desired therapeutic effect even when plasma concentrations are elevated into the toxic range. If the desired therapeutic effect is achieved at suboptimal plasma concentrations, every attempt should be made to avoid the prescription of additional drugs simply to increase the plasma concentration into what is commonly referred to as the therapeutic range. Obviously, the interpretation of plasma drug concentration must take into account the various factors that can alter the steady state plasma concentrations achieved on a given dosage form [54].

\subsection{Therapeutic Drug Monitoring (TDM)}

Individualizing a patient's drug therapy to obtain the optimum balance between therapeutic efficacy and the occurrence of adverse events is the physician's goal. However, achieving this goal is not always straight forward, being complicated by within and between patient variability in both pharmacokinetics and pharmacodynamics. In the early 1960's new analytical techniques became available allowing the measurement of the low drug concentrations seen in biological fluids during drug treatment. This offered the opportunity to reduce the pharmacokinetic component of variability by controlling drug therapy using concentrations in the body rather than by dose alone. This process became known as therapeutic drug monitoring [55].

The aim of TDM is to optimize pharmacotherapy by maximizing therapeutic efficacy, while minimizing adverse events, in those instances where the blood concentration of the drug is a better predictor of the desired effect(s) than the dose. The reasons why these principles have gained wide acceptance include the following: (1) although imperfect, a better relationship often exists between the effect of a given drug and its concentration in the blood than between the dose of the drug and the effect; (2) a thorough understanding of pharmacokinetics, i.e., the processes of drug absorption, distribution, metabolism, and drug excretion in individual patients and in patient populations is available; and (3) the development of reliable and relatively easy to use drug-monitoring assays. In addition, TDM can also be useful in cases in which compliance is in question, where it is not clear if the right drug is being taken, where dosage adjustment is required as a result of drug-drug or drug-food interactions, and where intoxication is suspected.

TDM is more than simply the analysis of a single drug concentration in the blood of a patient and a report of this number. It also comprises interpretation of the value measured using the mathematical (pharmacokinetic) principles mentioned above, drawing the appropriate 
conclusions about the result, and advising the physician who ordered the test how to optimize treatment. It is important to apply a uniform definition of TDM here, because different definitions have previously been used in cost-effectiveness studies and reviews of TDM. Consequently, comparisons have been made based on different approaches, which may influence the results. The International Association for Therapeutic Drug Monitoring and Clinical Toxicology has adopted the following definition:

Therapeutic drug monitoring is defined as the measurement made in the laboratory of a parameter that, with appropriate interpretation, will directly influence prescribing procedures. Commonly the measurement is in a biologic matrix of a prescribed xenobiotic, but it may also be of an endogenous compound prescribed as replacement therapy in an individual who is physiologically or pathologically deficient in that compound. This definition places TDM within the total therapeutic approach and should give not only more emphasis to the medication and patient-safety aspects of pharmacotherapy, but also more insight into why there are differences in efficacy among different patients. This definition implies that clinical pharmacologists have an active involvement in drug therapy, something that is not yet realized in many countries [56].

\subsubsection{Why TDM for immunosuppressants?}

For a drug to be a suitable candidate for therapeutic drug monitoring it must satisfy the following criteria [55]:

1. There should be a clear relationship between drug concentration and effect.

2. The drug should have a narrow therapeutic index; that is, the difference in the concentrations exerting therapeutic benefit and dose causing adverse events should be small.

3. There should be considerable between-subject pharmacokinetic variability and, therefore, a poor relationship between dose and drug concentration/response.

4. The pharmacological response of the drug should be difficult to assess or to distinguish form adverse events.

The most commonly used immunosuppressants require TDM because of their narrow therapeutic index and significant variability in blood concentrations between individuals. In transplant recipients, both supratherapeutics and subtherapeutics drug concentrations can have devastating results. At subtherapeutics drug concentrations, the transplant recipient is at risk for allograft rejection. At supratherapeutics drug concentrations, the patient is at risk for over-immunosuppression which can potentially lead to infection or drug specific side effects. It is it known that neurological and gastrointestinal side effects occur more frequently at higher concentrations of TRL [53]. Immunosuppressants display significant interindividual variability in plasma drug concentrations, which creates the demand for TDM when such drugs are used.

\subsubsection{Factors contributing to the variability}

Immunosuppressants display significant interindividual variability in plasma drug concentrations, which creates the demand for TDM when such drugs are used. It is appropriate to 
look into the multitude of factors that contribute to the interindividual variability. Some of the factors include drug-nutrients interactions, drug-disease interactions, renal insufficiency, inflammation and infection, gender, age, polymorphism and liver mass. Drug nutrient interactions are becoming very widely appreciated. The metabolism of drugs sometimes also depends on the type of diet taken by the patients. Renal transplant patients may have reduced oral bioavailability for TRL. When given with meals, especially with high fat content food, oral bioavailability of TRL decreases [57].

To avoid the possible effect of food on TRL bioavailability, the drug should be given at a constant time in relation to meals. Several studies have demonstrated that grapefruit juice can increase plasma concentrations of CsA by inhibiting CYP3A-mediated metabolism and by increasing drug absorption via inhibition of P-glycoprotein (P-gp) efflux transporters. Also, oral TRL should not be taken with grapefruit juice since this vehicle inhibits CYP3A4 and/or P-gp contained in the gastrointestinal tract and markedly increases bioavailability. Similarly, drug disease interactions can also contribute to interindividual variability in plasma concentration of immunosuppressants. Renal insufficiency can result in an altered free fraction of MPA due to the reduction in protein binding. MMF is rapidly converted to its active form, MPA, upon reaching the systemic circulation. MPA is metabolized to its glucuronide metabolite, MPA glucuronide (MPAG), by glucoronyl transferases in the liver and possibly elsewhere. MPAG is then excreted by the kidney. MPA is extensively and avidly bound to serum albumin. Previous studies have demonstrated that it is only the free (non-protein-bound) fraction of MPA that is available to exert its action. In vivo and in vitro studies demonstrate that renal insufficiency decreases the protein binding of MPA and increases free drug concentrations. This decrease in protein binding seems to be caused both by the uremic state itself and by competition with the retained metabolite MPAG. The disposition of MPA in patients with severe renal impairment may be significantly affected by this change in protein binding [58]. The concomitant administration of TRL and nonsteroidal anti-inflammatory drugs has been described as a possible cause of increased TRL nephrotoxicity because of the reduction of vasodilator prostaglandin synthesis through a blockade of the enzyme cyclo-oxygenase. Coadministration of ibuprofen and TRL has resulted in acute renal failure. Drugs such as aminoglycosides, cotrimoxazole (trimethoprim/sulfamethoxazole), amphotericin B and aciclovir, which cause significant renal dysfunction on their own, may also enhance TRL nephrotoxicity in the absence of careful monitoring of both renal function and drug concentrations [59].

It has been demonstrated that the in vitro metabolism of CsA in human liver microsomes was significantly reduced by TRL [60]. Interaction between MMF and TRL or CsA is probably related to a possible inhibitory effect of TRL on MPA metabolism and an inhibition of the enterohepatic recirculation of MPA by CsA, resulting in a substantial reduction in the MMF dosage when associated with TRL as compared with CsA. This has been reported in pediatric renal allograft patients and animal models [61,62].

Gender also influences drug concentration. Biologic differences exist between men and women that can result in differences in responses to drugs. Both pharmacokinetic and pharmacodynamic differences between the sexes exist, with more data on pharmacokinet- 
ic differences. Bioavailability after oral drug dosing, for CYP3A substrates in particular, may be somewhat higher in women compared to men [63]. It is known that MPA is primarily metabolized in the liver to its MPAG derivative. Morissette et al., found that men treated with MMF and TRL showed a lower ratio than patients treated with this couple of drugs, confirming that TRL inhibits glucuronidation of MPA. Because MPAG can favor the elimination of MPA, they concluded that gender differences and cotreatment with TRL must be taken into consideration when MMF is being administered [64]. Velickovic et al., investigated the gender differences in pharmacokinetics of TRL, their result show remarkable gender-related differences between women and men after the first oral dose among kidney transplant recipients on quaternary immunosuppressive therapy, including TRL, MMF, methylprednisolone and basiliximab [65].

Likewise, age can also contribute to interindividual difference in immunosuppressant plasma concentration. Pharmacokinetic parameters observed in adults may not be applicable to children, especially to the younger age groups. In general, patients younger than 5 years of age show higher clearance rates regardless of the organ transplanted or the immunosuppressive drug used [66]. Young children (1-6 years of age) appear to need higher doses per kilogram body weight of TRL than older children and adults to maintain similar trough concentrations. The reason for this age-related faster clearance rate is unknown [67]. Pediatric transplant recipients require higher doses of CsA to maintain blood concentrations equal to those found in adults [68]. Studies using intravenous CsA demonstrate that this is not because of any metabolic differences, as CsA clearance is not related to age [69].

Polymorphism has demonstrated functional consequences of many drug metabolizing enzymes. For example, CsA is known substrate for CYP3A4/5 and P-gp. CYP3A5 is one of the main CYP3A enzymes and its expression is clearly polymorphic and shows ethnic dependence. TRL is primarily metabolized by cytochrome P450(CYP)3A enzymes in the gut wall and liver. It is also a substrate for P-gp, which counter-transports diffused TRL out of intestinal cells and back into the gut lumen. Age-associated alterations in CYP3A and P-gp expression and/or activity, along with liver mass and body composition changes would be expected to affect the pharmacokinetics of TRL in the elderly [70]. The importance of interethnic differences in the pharmacokinetics of immunosuppressants has been recognized as having a significant impact on the outcome of transplantation. In a retrospective analysis Fitzimmons et al., found that the oral bioavailability of TRL in African American healthy volunteers and kidney transplant patients was significantly lower than in non-African Americans, but there was no statistically significant difference in clearance [71]. These results were confirmed in a healthy volunteer study. The absolute oral bioavailability of TRL in African American and Latin American subjects was significantly lower than in Caucasians. The results suggested that the observed ethnic differences in TRL pharmacokinetics were, instead, related to differences in intestinal P-glycoprotein-mediated efflux and CYP3A-mediated metabolism rather than differences in hepatic elimination [72].

Other ethnic groups such as the Japanese populations are not different from the Caucasian population because their transplant outcomes were comparable under usual TRL dosages [73]. All this factors contribute to the variability of immunosuppressant concentrations which has 
to be maintained within therapeutic range in order to achieve the optimal benefit of drug therapy, rendering TDM necessary for these drugs.

\section{Monitoring of individual immunosuppressive agents}

\subsection{Cyclosporine (CsA)}

The introduction of CsA in the early 1980s was immediately associated with an enhanced one year renal allograft survival; however, the argument for the therapeutic monitoring to optimize efficacy and safety, has been discussed in the last 25 years and it is still debated [74].

\subsubsection{Therapeutic monitoring}

\subsubsection{Trough concentration $\left(C_{0}\right)$ monitoring}

Over the past two decades, there have been changes to recommended CsA dosing, changes in concomitant medications, and one major change to the oral drug formulation. Lately, there has also been the introduction of generic formulations of CsA [75]. In 1988, in a prospective study showed that although $\mathrm{C}_{0}$ (trough concentration) levels of CsA correlated poorly with dose, Cmax was significantly correlated with dose, Area Under the Curve (AUC) and elimination half-life $\left(t_{1 / 2}\right)$. Those who suffered acute rejection had a significantly lower Cmax by $15-$ $31 \%$ [76]. The problem with this method for adjusting the dosage of CsA is that it relies on only one aspect of CsA pharmacokinetics, the predose or trough concentration. With the original formulation of CsA, Sandimmune ${ }^{\circledR}$, this was the best practice, but during the conversion of patients from that formulation to the improved formulation, Neoral ${ }^{\circledR}$ the $2 \mathrm{~h}$ post-dose concentration has been advocated as a single concentration monitoring alternative to C0 [77]. The microemulsion formulation of CsA, Neoral ${ }^{\circledR}$, makes CsA pharmacokinetics more predictable and reduces the effects of bile and food on absorption [78]. Nevertheless the predose concentration is still widely used in clinical practice. Currently, most transplant centers measure a single steady-state CsA concentration as either a $C_{0}$ predose trough or 2 hours postdose, while some conduct multiple measurements to determine CsA AUC estimates [79]. The target predose concentrations varied not only with transplanted organ and time after transplant but also with the analytical method used. The therapeutic range of CsA used by clinicians varies greatly according to the type of assay used to measure CsA and whether blood or serum concentrations are determined by the clinical laboratory.

Thus, it has reported by high pressure liquid chromatography, monoclonal fluorescence polarization immunoassay (monoclonal TDx assay, Abbott Diagnostics ${ }^{\circledR}$ ), or monoclonal radioimmunoassay (various manufacturers), the level of therapeutic concentrations in blood are 10-400 ng/mL. By high pressure liquid chromatography, monoclonal fluorescence polarization immunoassay (monoclonal TDx assay, Abbott Diagnostics ${ }^{\circledR}$ ), or monoclonal radioimmunoassay (various manufacturers), the level of therapeutic concentrations in serum are $50-150 \mathrm{ng} / \mathrm{mL}$. By polyclonal fluorescence polarization immunoassay (monoclonal TDx assay, Abbott Diagnostics ${ }^{\circledR}$ ), or polyclonal radioimmunoassay (various manufacturers) the level of 
therapeutic concentrations in blood are $200-800 \mathrm{ng} / \mathrm{mL}$, and by polyclonal fluorescence polarization immunoassay (monoclonal TDx assay, Abbott Diagnostics ${ }^{\circledR}$ ), or polyclonal radioimmunoassay (various manufacturers), the level of therapeutic concentrations in plasma are $100-400 \mathrm{ng} / \mathrm{mL}[79]$.

\subsubsection{Area under the blood concentration-time curve (AUC)}

The first steps towards the development of a more precise monitoring strategy for CsA resulted from the landmark studies by Lindholm and Kahan and Kahan et al., which identified a link between the pharmacokinetics of CsA and clinical outcomes in the individual transplant recipient $[80,81]$. The area under the concentration-time curve for CsA over a 12-hour drug administration interval $\left(\mathrm{AUC}_{0-12 \mathrm{~h}}\right.$ ) was a more precise predictor of graft loss and incidence of acute rejection than other parameters, including the $\mathrm{C}_{0}$. Since then, subsequent studies on the pharmacokinetics of CsA in renal transplant patients have identified that intrapatient variability in AUC values over time was directly correlated with the risk of chronic rejection $[77,82]$.

Proper calculation of AUC requires administration of a dose, followed by blood collection according to an intensive sampling strategy. Concentration values obtained are used to calculate AUC, usually by the trapezoidal method [78]. Some advantages of AUC monitoring are that it is the most precise indicator of drug exposure, can characterize abnormal absorption patterns, appears to be a predictor of clinical outcomes, generates a concentration-time profile, allows calculation of oral pharmacokinetic parameters, and reduces the problems associated with laboratory errors and single concentrations $[74,83,84]$.

Despite its appealing potential advantages, the major disadvantage of AUC monitoring is its inherent need for multiple blood samples. The increased number of samples required, makes AUC monitoring impractical for routine clinical use, more expensive in the short term because of increased sample collection, analysis and interpretation of results, and inconvenient for patients, especially those in an outpatient setting [77,85]. AUC has been advocated as a better parameter to monitor than trough concentrations, because trough concentrations give no indication of exposure to CsA. For example, 2 patients could have the same trough concentration, but one could have a much lower AUC and, therefore, exposure to CsA. Unfortunately, AUC monitoring is not clinically feasible because of the added time, expense and inconvenience required to collect a sufficient number of samples to properly calculate AUC. Although the full AUC for CsA has been demonstrated as being a sensitive monitoring tool, there may be an alternative approach to the determination of the degree and variability of CsA exposure in the individual patient $[77,83]$.

\subsubsection{Two hours post dose concentration monitoring $\left(C_{2}\right)$}

This approach, which is termed 'absorption profiling', has the underlying rationale that the 4hour absorption phase following administration provides measurements that are more informative than $\mathrm{C}_{0}$ monitoring in the assessment of likely CsA exposure and subsequent clinical response $[86,87]$. $\mathrm{AUC}_{0-4 \mathrm{~h}}$ monitoring is a sensitive tool used to optimize CsA immunosuppression in renal transplant recipients. However, the tool is not practical in the clinical 
setting because of 3 drawbacks: (1) it requires multiple sampling of blood for determination of the $\mathrm{AUC}_{0-4 \mathrm{~h}}$ (2) the actual value requires a mathematical calculation step, and (3) the test may be too expensive for many clinical hospitals or institutions because of the use of added costly laboratory tests for CsA concentrations and the subsequent increase in workload. Therefore, the search for a single blood-sampling point that best reflects the sensitivity of $\mathrm{AUC}_{0-4 \mathrm{~h}}$ was the focus of several research initiatives that resulted in a broad approval for $\mathrm{C}_{2}$ monitoring $[82,85]$. This method is done by measuring either the area under the blood CsA concentration-time curve in the first hours after dose, $\mathrm{AUC}_{0-4}$ or, more simply, by measuring the blood CsA concentration at 2 hours after dose, $C_{2}[82]$.

In the novo patients this monitoring method has led to result in the following clinical benefits compared with trough concentration monitoring [88]: (1) reduced incidence of acute rejection, (2) reduced severity of rejection episodes and (3) reduced incidence of nephrotoxicity.

\subsubsection{Bayesian forecasting}

The initial pharmacokinetic models for CsA were complicated by the nonlinear, segmented, zero order absorption of the drug from the gut $[77,89]$. Bayesian forecasting is a TDM tool that has been successfully used clinically in the monitoring of drugs that have a narrow therapeutic index, including antiepileptic drugs, theophylline and aminoglycosides; however, although Bayesian forecasting has proven useful clinically with other drugs, this is not the case with CsA [78]. Bayesian forecasting, in its modern form, was first proposed in 1979 by Sheiner et al. [90]. Since that time, user-friendly computer programs that perform this technique have become widely available. These programs are capable of calculating dosage regimens and pharmacokinetic parameters, as well as predicting drug concentrations by blending population values with patient-specific values [78]. However, these methods were technically complex and were not practical or successful for individualizing CsA therapy in a routine clinical setting and therefore did not gain widespread use. The introduction of Neoral, with its less variable and more predictable blood concentration profile, has rekindled interest in the pharmacokinetic modeling of CsA and in the use of Bayesian forecasting to predict CsA blood concentrations [77].

\subsection{Tacrolimus (TRL)}

The therapeutic range for TRL used by most transplantation centers is $5-20 \mathrm{ng} / \mathrm{mL}$ in blood. Although, plasma TRL concentrations have been measured and an equivalent therapeutic range in this matrix suggested $(0.5-2 \mathrm{ng} / \mathrm{mL})$, the two most widely used assays for the drug use blood samples. Because this drug is extensively bound to erythrocytes, blood concentrations average about 15 times greater than concurrently measured serum or plasma concentrations $[57,79,91]$. As a result, whole blood has become the principal sample used for TRL concentration monitoring, with extraction accomplished through cell lysis and protein denaturation steps that are similar or identical to those used for CsA analysis [51]. The pharmacokinetics of TRL is highly variable. Since TRL shares many of the pharmacokinetic and pharmacodynamic problems associated with CsA the rationale for TDM is similar. Although the feasibility of a limited sampling scheme to predict AUC 
has been demonstrated, as yet, through or predose whole blood concentration monitoring is still the method of choice [55].

\subsubsection{Therapeutic monitoring}

TRL whole-blood through concentrations have been found to correlate well with the area under the concentration-time curve measurements in liver, kidney and bone marrow transplant recipients $(\mathrm{r}=0.91-0.99)$. Thus, through concentrations are good index of overall drug exposure, and are currently used for routine monitoring as part of patient care posttransplantation $[91,92]$. This approach offers the opportunity to reduce the pharmacokinetic variability by implementing drug dose adjustments based on plasma/blood concentrations. Drug levels are obtained as predose ( 12 hours after previous dose) trough concentrations in whole blood [88]. These trough levels correlate reasonably well with area under the curve, with total area under the curve being an accurate measure of drug exposure [94].

Therapeutic ranges of TRL after kidney transplantation are reported as a range for various times after transplant: $0-1$ month, $15-20 \mu \mathrm{g} / \mathrm{L} ; 1-3$ months, $10-15 \mu \mathrm{g} / \mathrm{L}$; and more than 3 months, $5-12 \mu \mathrm{g} / \mathrm{L}$ [95]. TRL blood concentrations are monitored 3 to 7 days a week for the first 2 weeks, at least three times for the following 2 weeks, and whenever the patient comes for an outpatient visit thereafter [96]. On the basis of the terminal half-life of TRL, it was suggested to start monitoring blood concentrations 2 to 3 days after initiation of TRL treatment after the drug has reached steady state. However it is important to reach effective drug concentrations early after transplantation to decrease the risk of acute rejection and to avoid excessive early calcineurin inhibitors concentrations that may be severely damaging after reperfusion of the transplanted organ [97].

The frequency of TDM of TRL should be increased in the case of suspected adverse events or rejection, when liver function is deteriorating, after dose adjustments of the immunosuppressants, change of route of administration, or change of drug formulations, when drugs that are known to interact with CYP3A or P-gP are added or discontinued, or when their doses are changed, in case of severe illness that may affect drug absorption or elimination such as severe immune reactions and sepsis, or if noncompliance is suspected [98].

\subsection{Mycophenolic acid (MPA)}

In 1995, for preventing rejection in renal transplant patients, MMF, the morpholinoethyl ester prodrug from MPA was approved for clinical use. This drug has since become the predominant anti-metabolite immunosuppressive used in the transplant setting. Although the current labeling information for MMF does not indicate any need for therapeutic monitoring of plasma MPA concentrations, there were a number of studies showing a relationship between MPA pharmacokinetics and clinical outcome [99]. Definitive determination of the pharmacokinetics of the drug in renal allograft recipients after transplantation is not without difficulty. In principle, substantial changes in pharmacokinetics could be produced by changes following transplantation, both in the immediate post-transplant period (reflecting rapid alterations in drug therapy, renal function, hemo- 
dynamics and gastrointestinal motility) as well as more gradual changes (reflecting change in bodyweight, plasma proteins and organ function) [100]. The greatest variability in MPA pharmacokinetic is noted in the initial 2 months following transplantation, when adequate immunosuppression is critical to graft function and survival. It has also become apparent from longer term pharmacokinetic studies that exposure to MPA increases over time due to reduced clearance of the drug. A possible additional factor that could contribute to the higher oral clearance of MPA early after transplantation is corticosteroid therapy, which is significantly higher in that period but then is tapered to low dose levels or completely withdrawn. Based upon the marked pharmacokinetic variability observed with MPA and the pharmacodynamic relationship of pharmacokinetic parameters to rejection outcome, several scientific societies and consensus conferences have advocated the use of concentration monitoring for patients undergoing treatment with MMF or enteric-coated MPA [101].

\subsubsection{Therapeutic monitoring}

The incorporation of MMF into immunosuppressive regimens has been associated with decrease rates of acute rejection and decreased chronic allograft loss. Indications for TDM of mycophenolates were reviewed in a consensus meeting [101]. They included high-risk patients, patients with delayed graft function, or patients with immunosuppressive protocols excluding induction therapy or steroids or calcineurin inhibitor or patients with calcineurin minimization. Most of these patients (especially high-risk patients) are often excluded from the clinical trials. In fact, MPA TDM is currently only used in a few transplant centers on a routine basis, whereas a few others only checked MPA exposure in case of unexpected acute rejection or adverse event or drug interaction. Most of the centers never measure MPA. It is clear that the use of MPA TDM is conditioned by the faith of the physicians in its use, local availability of MPA measurements, and organization of the nursing staff [102].

\subsubsection{Trough concentration $\left(C_{0}\right)$ monitoring}

Although a relationship between AUC and outcome exists, the clinical utility of concentration monitoring, particularly $\mathrm{C}_{0}$ monitoring for $\mathrm{MMF}$, has been questioned. Over the past decade, several studies were conducted to evaluate the clinical utility of prospective concentration controlled MMF therapy. While these studies were anticipated to fully clarify the utility of monitored MMF therapy, the outcomes from these studies are conflicting and have done little to settle the controversies surrounding this area of therapeutic drug monitoring [100]. With trough concentration, plasma concentration of MPA is measured immediately before a dose, it is easy to measure because only -ask patient to return to give sample, it is immediately before a dose, and only requires single simple possible association between $C_{0}$ and decreased rejection noted in transplant recipients. However this method represents some disadvantages. Timing may not be accurate (depends on remembering time of last dose). Timing may vary from the "ideal" (12 h after last dose) by several hours. There is no high-level evidence of a strong association between $C_{0}$ and outcome, or between $C_{0}$ and $A U C_{0-12}, C_{0}$ is not a very informative time point for estimation of individual pharmacokinetic parameters. Single time-point samples 
such as the trough concentration or others do not correlate well with the MPA AUC, especially in the early posttransplantation period [103].

\subsubsection{Limited sampling strategies for estimation of MPA AUC}

The dose interval MPA $\mathrm{AUC}_{0-12} \mathrm{~h}$ is generally regarded as the most reliable pharmacokinetic parameter index of risk for acute rejection but is impractical to measure in routine clinical practice. Single time-point samples such as the trough concentration or others, do not correlate well with the MPA AUC, especially in the early posttransplantation period renal transplant patients and for regimens that include MMF plus CsA, TRL, or SRL [104]. Therefore, assessment of whether $\mathrm{C}_{0}$ concentrations or other single time points correlate well with the AUC is important for establishing routine monitoring of the drug. Apart of the $\mathrm{C}_{0}$ level other single time points after MMF dosing are examined for their ability to predict full AUC values. A full MPA AUC typically requires at least eight blood samples during 12 hour dose interval. In clinical practice this is impractical; therefore, abbreviated sampling schemes involving the collection of there to five plasma samples have been investigated. The abbreviated sampling approach has provided estimations of MPA AUC with high correlations $\left(r^{2}>0.8\right)$. Several models have been developed all of them in renal transplant patients [105-108].

\subsection{Sirolimus (SRL)}

SRL (formerly known as rapamycin) is a macrolide antibiotic with immunosuppressive properties that was introduced relatively recently (September 1999) into clinical practice for maintenance therapy in organ transplantation [109]. Pharmacokinetics studies of SRL in renal transplant patients have been shown great variability between patients. Several features contribute to the interpatient pharmacokinetic variability observed with SRL and can include any combination of the following: absorption, distribution, metabolism and/or excretion [110].

This drug presents a rapid gastrointestinal absorption ( $\mathrm{t}_{\max }$ from 0.33 to 5 hours) as well as a low (mean value 14\%) and variable bioavailability. It has been reported that SRL is a substrate for the multidrug P-glycoprotein transporter and that the biotransformation of SRL is mediated by CYP3A enzymes. Accordingly, considerable variability in its pharmacokinetic parameters may be expected (apparent blood clearance rates after oral administration from 87 to $416 \mathrm{~mL} / \mathrm{h} / \mathrm{kg}$ ). In addition, the disposition of SRL in humans includes a large volume of distribution, a long half-life (35 to 95 hours) and dose proportionality for Cmax and AUC. Also, some interracial variability and an influence of hepatic dysfunction have been noted with SRL [111]. Although structurally similar to TRL, SRL has a novel mechanism of action, which leads to synergy with CsA. The long half-life of the drug necessitates a loading dose to achieve therapeutic concentrations quickly, and also allows for once daily administration. Highly variable absorption and metabolism of the drug result in large differences in blood concentrations among patients receiving the same dose. Efficacy for the prevention of acute rejection episodes, and the rate of common adverse effects (thrombocytopenia, leucopenia and hypertriglyceridemia), are concentration-dependent [112]. 


\subsubsection{Therapeutic monitoring}

Clinical data suggest that the immunosuppressive efficacy and the occurrence and severity of adverse effects of SRL correlate with blood concentrations [112]. Drug interactions with concomitant immunosuppressant medications will alter SRL whole blood concentrations. The appropriate SRL through concentration at steady state $(\mathrm{Cmin}, \mathrm{ss})$ for acute rejection episode prophylaxis is a function of the concomitant immunosuppressive regimen. When it is used as base therapy with azathioprine and prednisone, a regimen stipulating initial $\mathrm{Cmin}$,ss values equal to $30 \mu \mathrm{g} / \mathrm{L}$ during the first 2 months, and $15 \mu \mathrm{g} / \mathrm{L}(\mathrm{LC} / \mathrm{UV}$ assay) thereafter, led to a $41 \%$ rate of acute rejection episodes among 41 cadaveric kidney transplant recipients [113].

When combined with MMF and prednisone, this SRL regimen was associated with a $27.5 \%$ rate of acute rejection episodes among 40 cadaveric renal transplant recipients. Indeed, the combination of SRL (Cmin,ss of 10 to $20 \mu \mathrm{g} / \mathrm{L}$; LC/UV assay) and basiliximab with late introduction of low dosage CsA has provided excellent prophylaxis of acute rejection episodes and renal function for primary, non-African-American recipients of cadaveric kidney transplants that displayed delayed graft function [112,114,115].

In purely Caucasian low-risk liver and kidney-pancreas transplant recipients, Cmin,ss of 6 to $12 \mu \mathrm{g} / \mathrm{L}$ (IMx® assay) in combination with low dosage TRL has been reported to yield low rates of acute rejection episodes and toxicity [116]. Because of the long half-life and extensive tissue distribution of the drug, steady-state concentrations are not reached before day 6 after initiation of therapy or after a dosage change. Thus, daily concentration monitoring is not necessary; the first SRL measurements should not be obtained before day 4 after inception of, or change in therapy. Thereafter, recommend monitoring Cmin,ss weekly for the first month and bi-weekly for the next month, targeting a 5 to $15 \mu \mathrm{g} / \mathrm{L}$ range if CsA is being used concomitantly at Cmin,ss concentrations of 75 to $150 \mu \mathrm{g} / \mathrm{L}$. If the patient fails to attain these values despite a dosage of $20 \mathrm{mg} /$ day, a full pharmacokinetic study should be performed to assess whether the defect is due to limited absorption or rapid clearance rates [112]. Modest correlation $(\mathrm{r}=0.59)$ exists between SRL dose and peak plasma concentration (Cmax) or AUC, but a good correlation $(r=0.85)$ exists between trough concentration prior to the dose (minimum Cmin,ss and AUC. For this reason, Cmin,ss is a simple and useful index for therapeutic monitoring of SRL $[112,117,118]$.

\subsection{Everolimus (EVL)}

In April 2010, EVL, a more water-soluble analog of SRL was approved for use in CsA-sparing regimens, including the requirement for adjusting EVL doses using target trough blood concentrations in renal transplant patients [51]. EVL, which has greater polarity than SRL, was developed in an attempt to improve the pharmacokinetic characteristics of SRL, particularly to increase its oral bioavailability. After a single oral dose of EVL 4mg in 12 healthy volunteers, it was absorbed rapidly (within 30 minutes after drug intake). The Cmax of EVL amounted to $44.2 \pm 13.3 \mu \mathrm{g} / \mathrm{L}$ and was reached $\left(t_{\max }\right)$ after 30 minutes (range $0.5-1$ hour). The AUC was 219 $\pm 69 \mu \mathrm{g}^{*} \mathrm{~h} / \mathrm{L}$. The overall absorption of EVL, like that of SRL, is probably affected by the activity of P-gp. It is recommended that patients should take the drug consistently with or without food to reduce fluctuations in drug exposure [119]. In an international study, the pharmaco- 
kinetics of EVL, were characterized over the first 6 months post-transplant in 731 patients receiving either 0.75 or $1.5 \mathrm{mg}$ bid EVL in addition to CsA and corticosteroids. The within- and between-patient variability of dose interval AUC was $27 \%$ and $31 \%$ respectively. There was no detectable influence of sex, age (16-66 years), or weight (42-132 kg) on AUC, but EVL exposure was significantly lower by an average of $20 \%$ in blacks. In a study of 659 AUC profiles the correlation between trough concentration and overall exposure (AUC) there was a significant linear correlation with a regression coefficient of 0.89 and corresponding coefficient of determination of 0.79 [120].

For example, see [121] reported that multiple daily dosing of EVL, in doses up to $5 \mathrm{mg} / \mathrm{day}$, is adequately well tolerated as add-on therapy in stable renal transplant patients receiving maintenance Neoral ${ }^{\circledR}$ immunosuppression. Similar degrees of correlation between EVL trough concentration and thrombocytopenia, leukopenia, hypertriglyceridemia, or hypercholesterolemia in 54 stable renal transplant patients (18-68 years) were found.

\subsubsection{Therapeutic drug monitoring}

EVL is a drug with a narrow therapeutic index. The limited and variable bioavailability, intrinsic interindividual pharmacokinetic variability, the number of factors affecting the pharmacokinetics, and the number of drug interactions limits the use of fixed doses of this drug. The EVL Cmin is a good surrogate marker of EVL exposure (AUC), and correlates with pharmacological response and clinical outcomes. Therefore, prospective dose adjustments to obtain and maintain a therapeutic EVL Cmin have the potential to improve efficacy and reduce toxicity [122].

A role for EVL drug monitoring has been suggested because of the potential for improving efficacy and reducing adverse effects, the EVL Cmin is a good surrogate marker of EVL exposure (AUC), and correlates with pharmacological response and clinical outcomes. Therefore, prospective dose adjustments to obtain and maintain a therapeutic EVL Cmin have the potential to improve efficacy and reduce toxicity [123]. Mere clinical monitoring of efficacy is insufficient because clinical presentations of graft rejection vary for each patient and are nonspecific. Thus, some authors have used a previously published 9-step decision-making algorithm to evaluate the utility of TDM for EVL. The recommended therapeutic range for EVL is a trough concentration of 3 to $8 \mathrm{ng} / \mathrm{mL}$, as concentrations over $3 \mathrm{ng} / \mathrm{mL}$ have been associated with a decreased incidence of rejection, and concentrations $>8 \mathrm{ng} / \mathrm{mL}$ with increased toxicity. Patients on EVL who have problems with absorption, who take concurrent cytochrome P450 inhibitors or inducers, or are noncompliant will attain the greatest benefit from therapeutic drug monitoring [124].

\section{Advances in immunosuppression - Future trends}

Maintenance immunosuppressive therapy over the past decade has become more diversified. Until the mid-1990s, CsA and azathioprine were the cornerstones in maintenance immunosuppressive therapy. Today, these agents have been largely replaced by the newer agents TRL 
and MMF. Triple immunosuppression continues to be the standard, and corticosteroids are still part of most widely used immunosuppressive protocols. More effective immunosuppression has reduced the incidence of acute rejection without a reduction in patient survival [125]. Calcineurin inhibitors are still the cornerstone of current immunosuppressive therapy, but have important cardiovascular and oncogenic side effects and nephrotoxicity effects that contributes to the multifactorial process called "chronic allograft dysfunction", the leading cause of chronic allograft failure among kidney transplant recipients. New drugs, with a different mechanism of action, are being developed focusing on a better balance between drug efficacy and toxicity. These novel compounds interfere with either T-cell mediated or antibodymediated rejection [126].

A number of novel drugs are currently under investigation in Phase I, II, or III clinical trials primarily to replace the nephrotoxic but highly effective calcineurin inhibitors. ISA247 (voclosporine) is a CsA analog with reduced nephrotoxicity in Phase III study. AEB071 (sotrastaurin), a protein kinase C inhibitor, and CP-690550, a JAK3 inhibitor, are small molecules in Phase II studies EVL is derived from the mTOR inhibitor SRL and is in Phase III study. Belatacept is a humanized antibody that inhibits T-cell costimulation and has shown encouraging results in multiple Phase II and III trials. Alefacept and Efaluzimab are humanized antibodies that inhibit T-cell adhesion and are in Phase I and II clinical trials [127]. Finally, the exciting field of tissue engineering and stem cell biology with the repopulation of decellularized organs is ushering in a new paradigm for transplantation. The era of simplified immunosuppression regimens devoid of toxicities is upon us with the promise of dramatic improvement in long term survival [128].

\section{Conclusions}

Monitored drug therapy has undergone a tremendous change over the past quarter of a century with the increasing availability of advanced techniques like liquid chromatography with tandem mass spectrometry detection and immunoassays. Currently, the possibility of accurately and specifically measuring almost any drug in any biological fluid is a reality, and while TDM has become a standard of care for most immunosuppressive drugs, TDM practices will continue to evolve with the field of transplantation. New immunosuppressives, such as sotrastaurin, exhibit pharmacokinetic variability comparable to that seen with currently used immunosuppressive drugs and may benefit from monitoring therapy [129]. Although TDM of biologic drugs such as belatacept have not been reported in clinical trials to date, potentially useful pharmacodynamic assays that can be performed on blood specimens have been described [51,130]. The information gained through further study in these complex regimens should provide innovative strategies and new immunosuppressive agents that will serve to extend the functional life of allografts without toxicity or infection. 


\section{Author details}

Ana Luisa Robles Piedras*, Minarda De la O Arciniega and Josefina Reynoso Vázquez

*Address all correspondence to: roblesa@uaeh.edu.mx

Academic Area of Pharmacy, Institute of Health Sciences, Autonomous University of Hidalgo State, Mexico

\section{References}

[1] Krensky AM, Vincenti F, Bennett WM. Immunosuppressants, Tolerogens, and Immunostimulants. In: Brunton L. (ed) Goodman and Gilman's The Pharmacological Basis of Therapeutics $11^{\text {th }}$ ed. McGraw-Hill Co. New York, NY. 2006. p1405-1431.

[2] Kahan BD. Cyclosporine. New England Journal of Medicine 1989;32:1725-1738.

[3] Khanna A, Li B, Stenzel KH, Suthanthiran M. Regulation of new DNA synthesis in mammalian cells by cyclosporine. Demonstration of a transforming growth factor betadependent mechanism of inhibition of cell growth. Transplantation 1994;57:577-582.

[4] Freeman DJ. Pharmacology and pharmacokinetics of cyclosporine. Clinical Biochemistry 1991;24:9-14.

[5] Fairley JA. Intracellular targets of cyclosporine. Journal of the American Academy of Dermatology 1990;23:1329-1334.

[6] Halloran PF, Madrenas J. The mechanism of action of cyclosporine: a perspective for the 90's. Clinical Biochemistry 1991;24:3-7.

[7] Schreiber SL, Crabtree GR. The mechanism of action of cyclosporin A and FK506. Immunology Today 1992;13:136-142.

[8] Aszalos A. Cyclosporin: some aspects of its mode of action. A review. Journal of Medicine 1988;19:297-316.

[9] Product Information. Sandimmune ${ }^{\circledR}$ oral capsules, oral solution, intravenous injection, cyclosporine oral capsules, oral solution, intravenous injection. Novartis Pharmaceuticals Corporation, East Hanover, NJ. 2010.

[10] Cush JJ, Tugwell P, Weinblatt M, Yocum D. US consensus guidelines for the use of cyclosporin A in rheumatoid arthritis. Journal of Rheumatology 1999;26(5):1176-1186.

[11] Charnick SB, Nedelman JR, Chang CT, Hwang DS, Jin J, Moore MA, Wong R. Description of blood pressure changes in patients beginning cyclosporin A therapy. Therapeutic Drug Monitoring 1997;19:17-24. 
[12] de Mattos AM, Olyaei AJ, Bennett WM. Nephrotoxicity of immunosuppressive drugs: long-term consequences and challenges for the future. American Journal of Kidney Diseases 2000;35(2):333-346.

[13] Ballantyne CM, Podet EJ, Patsch WP, Harati Y, Appel V, Gotto AM Jr, Young JB. Effects of cyclosporine therapy on plasma lipoprotein levels. The Journal of the American Medical Association 1989;262:53-56.

[14] McGaw WT, Porter H. Cyclosporine-induced gingival overgrowth: an ultrastructural stereologic study. Oral Surgery, Oral Medicine, Oral Pathology 1988;65(2):186-190.

[15] Daly CG. Resolution of cyclosporin A (CsA)-induced gingival enlargement following reduction in CsA dosage. Journal of Clinical Periodontology 1992;19:143-145.

[16] Wong W, Hodge MG, Lewis A, Sharpstone P, Kingswood JC. Resolution of cyclosporininduced gingival hypertrophy with metronidazole. Lancet 1994;343:986.

[17] Shapiro R. Tacrolimus in pediatric renal transplantation: A review. Pediatric Transplantation 1998;2:270-276.

[18] Plosker GL. Foster RH. Tacrolimus: a further update of its pharmacology and therapeutic use in the management of organ transplantation. Drugs 2000;59:323-389.

[19] Tocci MJ, Matkovich DA, Collier KA, Kwok P, Dumont F, Lin S, Degudicibus S, Siekierka JJ, Chin J, Hutchinson NI. FK-506 selectively inhibits expression of early T cell activation genes. The Journal of Immunology 1989;143:718-726.

[20] Kay JE, Moore AL, Doe SE, Benzie CR, Schönbrunner R, Schmid FX, Halestrap AP. The mechanism of action of FK 506. Transplantation Proceedings 1990;22(1):96-99.

[21] Peters DH, Fitton A, Plosker GL, Faulds D. Tacrolimus: a review of its pharmacology, and therapeutic potential in hepatic and renal transplantation. Drugs 1993;46:746-794.

[22] Rauch MC, San Martín A, Ojeda D, Quezada C, Salas M, Cárcamo JG, Yañez AJ, Slebe JC, Claude A. Tacrolimus causes a blockage of protein secretion which reinforces its immunosuppressive activity and also explains some of its toxic side-effects. Tacrolimus causes a blockage of protein secretion which reinforces its immunosuppressive activity and also explains some of its toxic side-effects. Transplant Immunology 2009;22(1-2): 72-81.

[23] Product Information: PROGRAF® oral capsules, IV injection, tacrolimus oral capsules, IV injection. Astellas Pharma US, Inc. (per manufacturer), Deerfield, IL. 2011.

[24] Henry ML. Cyclosporine and tacrolimus (FK506): a comparison of efficacy and safety profiles. Clinical Transplantation 1999;13:209-220.

[25] Pham SM, Kormos RL, Hattler BG, Kawai A, Tsamandas AC, Demetris AJ, Murali S, Fricker FJ, Chang HC, Jain AB, Starzl TE, Hardesty RL, Griffith BP. A prospective trial of (FK 506) in clinical heart transplantation: intermediate-term results. The Journal of Thoracic and Cardiovascular Surgery 1996;111:764-772. 
[26] AM, Furth SL, Case BW, Wise B, Colombani PM, Fivush BA. Evaluation of neurotoxicity in pediatric renal transplant recipients treated with tacrolimus (FK506). Clinical Transplantation 1997;11:412-414.

[27] Krentz AJ, Dousset B, Mayer D, McMaster P, Buckels J, Cramb R, Smith JM, Nattrass M. Metabolic effects of cyclosporin A and FK 506 in liver transplant recipients. Diabetes 1993;42:1753-1759.

[28] Ardestani F, Fatemi SS, Yakhchali B. Evaluation of mycophenolic acid production by Penicillium brevicompactum MUCL 19011 in batch and continuous submerged cultures. Biochemical Engineering Journal 2010;50(3):99-103.

[29] Oremus M, Zeidler J, Ensom MHH. Utility of monitoring mycophenolic acid in solid organ transplant patients. Evidence Report/Technology Assessment No. 164. AHRQ Publication No.08-E006. Rockville, MD: Agency for Healthcare Research and Quality. 2008. http://www.ahrq.gov/downloads/pub/evidence/pdf/mpa/mpaorgan.pdf (accessed 3 August 2012).

[30] Groth CG, Ohlman S, Gannedahl G, Ericzon BG. New immunosuppressive drugs in transplantation. Transplantation Proceedings 1993;25:2681-2683.

[31] Eugui EM, Mirkovich A, Allison AC. Lymphocyte-selective antiproliferative and immunosuppressive effects of mycophenolic acid in mice. Scandinavian Journal of Immunology 1991;33:175.

[32] Bumgardner GL, Roberts JP. New immunosuppressive agents. Gastroenterology Clinics of North America 1993;22:421-449.

[33] Butani L, Palmer J, Baluarte HJ, Polinsky MS. Adverse effects of mycophenolate mofetil in pediatric renal transplant recipients with presumed chronic rejection. Transplantation 1999;68:83-86.

[34] Product Information. CellCept ${ }^{\circledR}$ oral tablets, capsules, suspension and intravenous injection, mycophenolate mofetil oral tablets, capsules, suspension, mycophenolate mofetil hydrochloride intravenous injection. Roche Laboratories Inc., Nutley, NJ. 2009.

[35] Kuypers DR, Le Meur Y, Cantarovich M, Tredger MJ, Tett SE, Cattaneo D, Tönshoff B, Holt DW, Chapman J, Gelder T; Transplantation Society (TTS) Consensus Group on TDM of MPA. Consensus report on therapeutic drug monitoring of mycophenolic acid in solid organ transplantation. Clinical Journal of the American Society of Nephrology 2010;5:341-358. http://ebookbrowse.com/transplante-consensus-report-therapeuticdrug-monitoring-mycophenolic-acid-pdf-d322644574 (accessed 3 August 2012).

[36] Watson CJ, Friend PJ, Jamieson NV, Frick TW, Alexander G, Gimson AE, Calne R. Sirolimus: a potent new immunosuppressant for liver transplantation. Transplantation 1999;67(4):505-509. http://www.centerspan.org/pubs/transplantation/1999/0227/ tr049900505o.pdf (accessed 3 August 2012).

[37] Kelly PA, Gruber SA, Behbod F, Kahan BD. Sirolimus, a new potent immunosuppressive agent. Pharmacotherapy 1997;17:1148-1156. 
[38] Morris RE. Mechanisms of action of new immunosuppressive drugs. Kidney International 1996;49(53):S26-S38.

[39] Brattström C, Wilczek H, Tydén G, Böttiger Y, Säwe J, Groth CG. Hyperlipidemia in renal transplant recipients treated with sirolimus (Rapamycin). Transplantation 1998;65(9):1272-1274.

[40] Schuler W, Sedrani R, Cottens S, Häberlin B, Schulz M, Schuurman HJ, Zenke G, Zerwes HG, Schreier MH. SDZ RAD, a new rapamycin derivative. Transplantation 1997;64(1): $36-42$.

[41] Eisen HJ, Tuzcu EM, Dorent R, Kobashigawa J, Mancini D, Valantine-von Kaeppler HA, Starling RC, Sørensen K, Hummel M, Lind JM, Abeywickrama KH, Bernhardt P; RAD B253 Study Group. RAD B253 Study Group. Everolimus for the prevention of allograft rejection and vasculopathy in cardiac-transplant recipients. The New England Journal of Medicine 2003;349:847-858.

[42] van Rossum HH, Romijn FP, Smit NP, de Fijter JW, van Pelt J. Everolimus and sirolimus antagonize tacrolimus based calcineurin inhibition via competition for FK-binding protein 12. Biochemical Pharmacology 2009;77(7):1206-1212.

[43] Sánchez-Fructuoso AI, Ruiz JC, Pérez-Flores I, Gómez Alamillo C, Calvo Romero N, Arias M. Comparative analysis of adverse events requiring suspension of mtor inhibitors: everolimus versus sirolimus. Transplantation Proceedings 2010;42(8): 3050-3052.

[44] Moldawer NP, Wood LS. Management of key adverse events associated with everolimus therapy. Kidney Cancer Journal 2010;8(2):51-59. http://www.kidney-cancerjournal.com/emag/v8n2/pageflip.htm (accessed 3 August 2012).

[45] Afzali B, Taylor AL, Goldsmith DJ. What we CAN do about chronic allograft nephropathy: Role of immunosuppressive modulations. Kidney International, 2005;68:2429-2443.

[46] Danovitch GM. Immunosuppressive medications for renal transplantation: A multiple choice question. Kidney International 2001; 59:388-402.

[47] Gabardi S, Martin ST, Roberts KL, Grafals M. Induction immunosuppressive therapies in renal transplantation. American Journal of Health-System Pharmacy 2011;68(1): 211-218.

[48] Helal I, Chan L. Steroid and calcineurin inhibitor-sparing protocols in kidney transplantation. Transplantation Proceedings 2011;43:472-477.

[49] Ponticelli C. Present and future of immunosuppressive therapy in kidney transplantation. Transplantation Proceedings 2011;43: 2439-2440.

[50] Budde K, Glander P. Pharmacokinetic principles of immunosuppressive drugs. Annals of Transplantation 2008;13(3):5-10. 
[51] Milone MC., Shaw LMJ. Therapeutic Drug Monitoring for Immunosuppressive Agents. In: Kaplan B., Burkhart JG., Lakkis FG. (ed.) Immunotherapy in Transplantation: Principles and Practice. USA: Wiley-Blackwell; 2012. p95-113.

[52] Evans W. General Principles of Clinical Pharmacokinetics. In: Burton ME., Shaw LM., Schentag JJ., Evans WE. (ed) Applied Pharmacokinetics and Pharmacodynamics. Principles of Therapeutic Drug Monitoring. USA: Williams and Wilkins; 2006. p3-7.

[53] Kang JS, Lee MH. Overview of Therapeutic Drug Monitoring. The Korean Journal of Internal Medicine 2009;24(1):1-10. http://www.ncbi.nlm.nih.gov/pmc/articles/ PMC2687654/pdf/kjim-24-1.pdf (accessed 6 July 2012).

[54] Peppinger C., Massoud N. Therapeutic Drug Monitoring. In: Benet L., Massoud N., Gambertoglio J. (ed.) Pharmacokinetic Basis for Drug Treatment. New York: Raven Press; 1985. p367-393.

[55] Johnston A, Holt DW. Therapeutic drug monitoring of immunosuppressant drugs. British Journal of Clinical Pharmacology 1999; 47(4): 339-350.

[56] Neef C, Touw DJ, Stolk LM. Therapeutic Drug Monitoring in Clinical Research. Pharmaceutical Medicine.2008;22(4):235-44. http://adisonline.com/pharmaceuticalmedicine/Abstract/2008/22040/Therapeutic_Drug_Monitoring_in_Clinical_Research. 4.aspx (accessed 6 July 2012).

[57] Venkataramanan R, Swaminathan A, Prasad T, Jain A, Zuckerman S, Warty V, McMichael J, Lever J, Burckart G, Starzl T. Clinical pharmacokinetics of tacrolimus. Clinical Pharmacokinetics 1995;29(6):404-30.

[58] Meier-Kriesche HU, Shaw LM, Korecka M, Kaplan B. Pharmacokinetics of mycophenolic acid in renal insufficiency. Therapeutic Drug Monitoring 2000;22(1):27-30.

[59] Mignat C. Clinically significant drug interactions with new immunosuppressive agents. Drug Safety 1997;16:267-78

[60] Omar G, Shah IA, Thomson AW, Whiting PH, Burke MD. FK 506 inhibition of cyclosporine metabolism by human liver microsomes. Transplantation Proceedings 1991;23(1 Pt 2):934-5.

[61] Filler G, Lampe D, Mai I, Strehlau J, Ehrich JH. Dosing of MMF in combination with tacrolimus for steroid-resistant vascular rejection in pediatric renal allografts. Transplant International 1998;11 Suppl 1:S82-5.

[62] van Gelder T, Klupp J, Barten MJ, Christians U, Morris RE. Comparison of the effects of tacrolimus and cyclosporine on the pharmacokinetics of mycophenolic acid. Therapeutic Drug Monitoring 2001;23(2):119-28.

[63] Schwartz JB. The influence of sex on pharmacokinetics. Clinical Pharmacokinetics 2003;42(2):107-21.

[64] Morissette P, Albert C, Busque S, St-Louis G, Vinet B. In vivo higher glucuronidation of mycophenolic acid in male than in female recipients of a cadaveric kidney allograft 
and under immunosuppressive therapy with mycophenolate mofetil. Therapeutic Drug Monitoring 2001;23(5):520-5.

[65] Velicković-Radovanović R, Mikov M, Paunović G, Djordjević V, Stojanović M, Cvetković T, Djordjević AC. Gender differences in pharmacokinetics of tacrolimus and their clinical significance in kidney transplant recipients. Gender Medicine 2011;8(1):23-31.

[66] del Mar Fernández De Gatta M, Santos-Buelga D, Domínguez-Gil A, García MJ. Immunosuppressive therapy for paediatric transplant patients: pharmacokinetic considerations. Clinical Pharmacokinetics 2002;41(2):115-35.

[67] de Wildt SN, van Schaik RH, Soldin OP, Soldin SJ, Brojeni PY, van der Heiden IP, Parshuram C, Nulman I, Koren G. The interactions of age, genetics, and disease severity on tacrolimus dosing requirements after pediatric kidney and liver transplantation. European Journal of Clinical Pharmacology 2011;67(12):1231-41.

[68] Cooney GF, Habucky K, Hoppu K. Cyclosporin pharmacokinetics in paediatric transplant recipients. Clinical Pharmacokinetics 1997;32(6):481-95.

[69] Jacqz-Aigrain E, Montes C, Brun P, Loirat C. Cyclosporine pharmacokinetics in nephrotic and kidney-transplanted children. European Journal of Clinical Pharmacology 1994;47(1):61-5.

[70] Staatz CE, Tett SE. Clinical pharmacokinetics and pharmacodynamics of tacrolimus in solid organ transplantation. Clinical Pharmacokinetics 2004;43(10):623-53.

[71] Fitzsimmons WE, Bekersky I, Dressler D, Raye K, Hodosh E, Mekki Q. Demographic considerations in tacrolimus pharmacokinetics. Transplantation Proceedings 1998;30(4): 1359-64.

[72] Mancinelli LM, Frassetto L, Floren LC, Dressler D, Carrier S, Bekersky I, Benet LZ, Christians U. The pharmacokinetics and metabolic disposition of tacrolimus: a comparison across ethnic groups. Clinical Pharmacology and Therapeutics 2001;69(1): 24-31.

[73] Ochiai T, Fukao K, Takahashi K, Endo T, Oshima S, Uchida K, Yokoyama I, Ishibashi M, Takahara S, Iwasaki Y. Phase III study of FK 506 in kidney transplantation. Japanese FK 506 Study Group. Transplantation Proceedings 1995;27(1):829-33.

[74] Citterio F. Evolution of the therapeutic drug monitoring of cyclosporine. Transplantation Proceedings 2004;36(2 Suppl):420S-425S.

[75] Trevillian P. Therapeutic drug monitoring. Nephrology 2007; 12, S57-S65.

[76] Kasiske BL, Heim-Duthoy K, Rao KV, Awni WM. The relationship between cyclosporin pharmacokinetic parameters and subsequent acute rejection in renal transplant recipients. Transplantation 1988;46: 716-22.

[77] Johnston A., Holt DW. Cyclosporine. In: Burton ME., Shaw LM., Schentag JJ., Evans WE. (ed) Applied Pharmacokinetics and Pharmacodynamics. Principles of Therapeutic Drug Monitoring. USA: Williams and Wilkins; 2006. p512-528. 
[78] Dumont RJ, Ensom MH. Methods for clinical monitoring of cyclosporin in transplant patients. Clinical Pharmacokinetics 2000;38(5):427-47.

[79] Bauer LA. Applied Clinical Pharmacokinetics. USA: McGraw-Hill; 2001.

[80] Lindholm A, Kahan BD. Influence of cyclosporine pharmacokinetics, trough concentrations, and AUC monitoring on outcome after kidney transplantation. Clinical Pharmacology and Therapeutics 1993;54:205-18.

[81] Kahan BD, Welsh M, Schoenberg L, Rutzky LP, Katz SM, Urbauer DL, Van Buren CT. Variable oral absorption of cyclosporine. A biopharmaceutical risk factor for chronic renal allograft rejection. Transplantation 1996; 62:599-606.

[82] Levy GA. C2 monitoring strategy for optimizing cyclosporin immunosuppression from the Neoral formulation. BioDrugs 2001;15(5):279-90.

[83] David-Neto E, Araujo LP, Feres Alves C, Sumita N, Romano P, Yagyu EM, Nahas WC, Ianhez LE. A strategy to calculate cyclosporin A area under the time-concentration curve in pediatric renal transplantation. Pediatric Transplantation 2002;6(4):313-18.

[84] Weber LT, Armstrong VW, Shipkova M, Feneberg R, Wiesel M, Mehls O, Zimmerhackl LB, Oellerich M, Tönshoff B; Members of the German Study Group on Pediatric Renal Transplantion. Cyclosporin A absorption profiles in pediatric renal transplant recipients predict the risk of acute rejection. Therapeutic Drug Monitoring 2004;26(4):415-24.

[85] Mahalati K, Belitsky P, West K, Kiberd B, Fraser A, Sketris I, Macdonald AS, McAlister $\mathrm{V}$, Lawen J. Approaching the therapeutic window for cyclosporine in kidney transplantation: a prospective study. Journal of the American Society of Nephrology 2001;12(4):828-33.

[86] Dunn CJ, Wagstaff AJ, Perry CM, Plosker GL, Goa KL. Cyclosporin: an updated review of the pharmacokinetic properties, clinical efficacy and tolerability of a microemulsion based formulation (neoral)1 in organ transplantation. Drugs 2001;61(13): 1957-2016.

[87] Keown PA. New concepts in cyclosporine monitoring. Current Opinion in Nephrology and Hypertension. 2002;11(6):619-26.

[88] Belitsky P, Dunn S, Johnston A, Levy G. Impact of absorption profiling on efficacy and safety of cyclosporin therapy in transplant recipients. Clinical Pharmacokinetics 2000;39(2):117-25.

[89] Grevel J, Post BK, Kahan BD. Michaelis-Menten kinetics determine cyclosporine steady-state concentrations: a population analysis in kidney transplant patients. Clinical Pharmacology and Therapeutics 1993;53(6):651-60. ABSTRACT

[90] Sheiner LB, Beal S, Rosenberg B, et al. Forecasting individual pharmacokinetics. Clinical Pharmacology \& Therapeutics 1979;26:294-305.

[91] Jusko WJ, Thomson AW, Fung J, McMaster P, Wong SH, Zylber-Katz E, Christians U, Winkler M, Fitzsimmons WE, Lieberman R. Consensus document: therapeutic monitoring of tacrolimus (FK-506). Therapeutic Drug Monitoring 1995;17(6):606-614. 
[92] Staatz C, Taylor P, Tett S. Low tacrolimus concentrations and increased risk of early acute rejection in adult renal transplantation. Nephrology Dialysis and Transplantation 2001;16(9):1905-9.

[93] Cattaneo D, Perico N, Remuzzi G. From pharmacokinetics to pharmacogenomics: a new approach to tailor immunosuppressive therapy. American Journal of Transplantation 2004;4(3):299-310.

[94] Kapturczak MH, Meier-Kriesche HU, Kaplan B. Pharmacology of calcineurin antagonists. Transplantation Proceedings 2004;36(2 Suppl):25S-32S.

[95] Scott LJ, McKeage K, Keam SJ, Plosker GL. Tacrolimus: a further update of its use in the management of organ transplantation. Drugs 2003;63(12):1247-97.

[96] Jusko WJ, Kobayashi M. Therapeutic monitoring of tacrolimus (FK 506). Therapeutic Drug Monitoring 1993;15(4):349.

[97] Shaw LM, Holt DW, Keown P, Venkataramanan R, Yatscoff RW. Current opinions on therapeutic drug monitoring of immunosuppressive drugs. Clinical Therapeutics $1999 ; 21(10): 1632-52$.

[98] Christians U., Pokaiyavanichkul T., Chan 1. Tacrolimus. In: Applied Pharmacokinetics and Pharmacodynamics: Principles of Therapeutic Drug Monitoring, 4th Ed., edited by Burton ME, Shaw LM, Schentag JJ, Evans WE, Philadelphia, Lippincott Williams \& Wilkins, 2006, pp 563-594.

[99] Bullingham RES, Nicholls A, Hale M. Pharmacokinetics of mycophenolate mofetil (RS-61443): a short review. Transplantation Proceedings 1996;28:925-29.

[100] Bullingham RE, Nicholls AJ, Kamm BR. Clinical Pharmacokinetics of Mycophenolate Mofetil. Clinical Pharmacokinetics 1998;34(6):429-455.

[101] van Gelder T, Le Meur Y, Shaw LM, Oellerich M, DeNofrio D, Holt C, Holt DW, Kaplan B, Kuypers D, Meiser B, Toenshoff B, Mamelok RD. Therapeutic drug monitoring of mycophenolate mofetil in transplantation. Therapeutic Drug Monitoring 2006;28(2): 145-54.

[102] Le Meur Y, Borrows R, Pescovitz MD, Budde K, Grinyo J, Bloom R, Gaston R, Walker RG, Kuypers D, van Gelder T, Kiberd B. Therapeutic drug monitoring of mycophenolates in kidney transplantation: report of The Transplantation Society consensus meeting. Transplantation Reviews 2011;25(2):58-64.

[103] Nawrocki A., Korecka M., Solari S., Kang J., Shaw LM.: Mycophenolic acid. In: Applied Pharmacokinetics and Pharmacodynamics: Principles of Therapeutic Drug Monitoring, 4th Ed., edited by Burton ME, Shaw LM, Schentag JJ, Evans WE, Philadelphia, Lippincott Williams \& Wilkins, 2006, pp 563-594.

[104] Shaw LM, Figurski M, Milone MC, Trofe J, Bloom RD. Therapeutic drug monitoring of mycophenolic acid. Clinical Journal of the American Society of Nephrology 2007;2(5): 1062-72. 
[105] Filler G, Mai I. Limited sampling strategy for mycophenolic acid area under the curve. Therapeutic Drug Monitoring 2000;22(2):169-73.

[106] Yeung S, Tong KL, Tsang WK, Tang HL, Fung KS, Chan HW, Chan AY, Chan L. Determination of mycophenolate area under the curve by limited sampling strategy. Transplantation Proceedings 2001;33(1-2):1052-3.

[107] Musuamba FT, Rousseau A, Bosmans JL, Senessael JJ, Cumps J, Marquet P, Wallemacq P, Verbeeck RK. Limited sampling models and Bayesian estimation for mycophenolic acid area under the curve prediction in stable renal transplant patients co-medicated with ciclosporin or sirolimus. Clinical Pharmacokinetics 2009;48(11):745-58.

[108] Pawinski T, Hale M, Korecka M, Fitzsimmons WE, Shaw LM. Limited sampling strategy for the estimation of mycophenolic acid area under the curve in adult renal transplant patients treated with concomitant tacrolimus. Clinical Chemistry 2002;48(9): 1497-504.

[109] Vasquez EM. Sirolimus: a new agent for prevention of renal allograft rejection. American Journal of Health System Pharmacy 2000; 57(7):437-48.

[110] Stenton SB, Partovi N, Ensom MH. Sirolimus: the evidence for clinical pharmacokinetic monitoring. Clinical Pharmacokinetics 2005;44(8):769-86.

[111] Ingle GR, Sievers TM, Holt CD. Sirolimus: continuing the evolution of transplant immunosuppression. Annals of Pharmacotherapy 2000;34:1044-55.

[112] Mahalati K, Kahan BD. Clinical Pharmacokinetics of Sirolimus. Clinical Pharmacokinetics 2001;40(8):573-585.

[113] Groth CG, Bäckman L, Morales JM, Calne R, Kreis H, Lang P, Touraine JL, Claesson K, Campistol JM, Durand D, Wramner L, Brattström C, Charpentier B. Sirolimus (rapamycin)-based therapy in human renal transplantation: similar efficacy and different toxicity compared with cyclosporine. Sirolimus European Renal Transplant Study Group. Transplantation 1999;67(7):1036-42.

[114] Hong JC, Kahan BD. Use of anti-CD25 monoclonal antibody in combination with rapamycin to eliminate cyclosporine treatment during the induction phase of immunosuppression. Transplantation 1999;68:701-4.

[115] Hong JC, Kahan BD. A calcineurin-free strategy for induction immunosuppression for delayed graft function in cadaveric kidney transplantation. Transplantation Proceedings 2001;33:1271-2.

[116] McAlister VC, Gao Z, Peltekian K, Domingues J, Mahalati K, MacDonald AS. Sirolimustacrolimus combination immunosuppression. Lancet 2000;355(9201):376-7.

[117] Zimmerman JJ, Kahan BD. Pharmacokinetics of sirolimus in stable renal transplant patients after multiple oral dose administration. Journal of Clinical Pharmacology 1997;37(5):405-15.

[118] Yatscoff RW, LeGatt DF, Kneteman NM. Therapeutic monitoring of rapamycin: a new immunosuppressive drug. Therapeutic Drug Monitoring 1993;15(6):478-82. 
[119] Kirchner GI, Meier-Wiedenbach I, Manns MP. Clinical pharmacokinetics of everolimus. Clinical Pharmacokinetics. 2004;43(2):83-95.

[120] Kovarik JM, Kaplan B, Silva HT, Kahan BD, Dantal J, McMahon L, Berthier S, Hsu CH, Rordorf C. Pharmacokinetics of an everolimus-cyclosporine immunosuppressive regimen over the first 6 months after kidney transplantation. American Journal of Transplantation 2003;3(5):606-13.

[121] Budde K, Neumayer HH, Lehne G, Winkler M, Hauser IA, Lison A, Fritsche L, Soulillou JP, Fauchald P, Dantal J; RADW 102 Renal Transplant Study Group Tolerability and steady-state pharmacokinetics of everolimus in maintenance renal transplant patients. Nephrology Dialysis Transplantation 2004;19(10):2606-14.

[122] Helio Tedesco-Silva Jr, Claudia Rosso Felipe, Tainá Veras de Sandes, Freitas, Marina Pontello Cristeli, Carolina Araújo Rodrigues, José Osmar Medina Pestana. Impact of everolimus: update on immunosuppressive therapy strategies and patient outcomes after renal transplantation. Transplant Research and Risk Management 2011;3:9-29.

[123] Kovarik JM, Tedesco H, Pascual J, Civati G, Bizot MN, Geissler J, Schmidli H. Everolimus therapeutic concentration range defined from a prospective trial with reducedexposure cyclosporine in de novo kidney transplantation. Therapeutic Drug Monitoring 2004;26(5):499-505.

[124] Mabasa VH, Ensom MH. The role of therapeutic monitoring of everolimus in solid organ transplantation. Therapeutic Drug Monitoring 2005;27(5):666-76.

[125] Shapiro R, Young JB, Milford EL, Trotter JF, Bustami RT, Leichtman AB. Immunosuppression: evolution in practice and trends, 1993-2003. American Journal of Transplantation 2005;5(4 Pt 2):874-86.

[126] Metalidis C, Kuypers DR. Emerging immunosuppressive drugs in kidney transplantation. Current Clinical Pharmacology 2011;6(2):130-6.

[127] Cooper JE, Wiseman AC. Novel immunosuppressive agents in kidney transplantation. Clinical Nephrology. 2010;73(5):333-43.

[128] Webber A, Hirose R, Vincenti F. Novel strategies in immunosuppression: issues in perspective. Transplantation 2011;91(10):1057-64.

[129] Kovarik JM, Steiger JU, Grinyo JM, Rostaing L, Arns W, Dantal J, Proot P, Budde K; Sotrastaurin Renal Transplant Study Group. Pharmacokinetics of sotrastaurin combined with tacrolimus or mycophenolic acid in de novo kidney transplant recipients. Transplantation 2011;91(3):317-22.

[130] Vincenti F, Charpentier B, Vanrenterghem Y, Rostaing L, Bresnahan B, Darji P, Massari P, Mondragon-Ramirez GA, Agarwal M, Di Russo G, Lin CS, Garg P, Larsen CP. A phase III study of belatacept-based immunosuppression regimens versus cyclosporine in renal transplant recipients (BENEFIT study). American Journal of Transplantation 2010;10(3):535-46. 